\title{
Study on Using Biological Sludge from Vinh Loc Industrial Park to Produce Composting Product
}

\author{
Ton That Lang ${ }^{1}$, Nguyen Thi Mai Thao ${ }^{1}$, Pham Vu Nhat Uyen ${ }^{1}$ and Dang Anh Tuan ${ }^{2}$ \\ 1. Environmental Department, University of Natural Resources and Environment, Ho Chi Minh City 00848, Vietnam \\ 2. Microbiology Department, University of Technology, Ho Chi Minh City 00848, Vietnam
}

\begin{abstract}
In order to examine the optimal design and operating parameters in composting of waste activated sludge, a series of experiments were conducted to discuss the optimal operating parameters for aerobic composting of waste activated sludge obtained from Vinh Loc Industrial Park that is located in Ho Chi Minh City. The study was done by optimizing the ratios of sludge/inactive fillers and sludge/microbial products to improve the composting efficiency. After 50 days of composting, the composts of all experiment batches met the microorganism-organic fertilizer standards of 10 TCN 526:2002. The study indicated that the highest efficiency decomposition was obtained at the ratio of a sludge/inactive fillers of 1/0.1 and sludge/microbial products of 1/0.05: TOC (Total Organic Carbon) reduced by $20.2 \%$, loss of Nitrogen was trivial $(0.53 \%)$, the highest temperature reached at $55.5{ }^{\circ} \mathrm{C}$ and lasting for 5 days which ensures elimination of pathogens. However, the addition of nitrogen compounds during the composting is necessary to ensure the compost product can meet the nitrogen standard of microorganism-organic fertilizer.
\end{abstract}

Key words: Biological sludge, microorganism-organic fertilizer, aerobic composting, reuse of sludge, inactive fillers.

\section{Introduction}

Sewage sludge, a product of wastewater treatment, is rich in nutrients and trace elements and could be re-used in agriculture as fertilizer and soil conditioner. High odour emission, high levels of heavy metals and toxic organic compounds, and the presence of potentially pathogenic microorganisms, demand pretreatment of sewage sludge before application in agriculture.

Composting is a successful strategy for the sustainable recycling of organic wastes. Since composting is an inexpensive, simple and environmentally sound process for waste disposal, the composting of thickened and dewatered undigested primary and secondary sludge has been widely applied [1]. Composting improves the handling characteristics of organic residue by reducing its volume and weight. Therefore, received increasing amounts of interest and have been developed for treatment of waste activated

Corresponding author: Ton That Lang, Ph.D., main research field: waste treatment. sludge [2]. Aerobic composting, which is the decomposition of manure or other organic materials in the presence of oxygen, is one of the waste activated sludge treatment processes. In the aerobic composting process, the decomposition of organic materials is promoted by adequate aeration. However, excessive aeration causes a change to the worse in composting because the temperature of the reactor and moisture content of the material decrease [3]. It is important, therefore, that the amount of aeration is managed at the appropriate level to conduct composting efficiently.

Waste activated sludge, in general, has a higher moisture content than is desired, a substance with a lower moisture content has to be added. Materials utilized for this purpose are called organic amendments or bulking agents [4]. The dewatered sludge might lack sufficient porosity for adequate aeration. Bulking agents are needed to provide structural support when the composting materials are too wet to maintain air spaces within the composting pile, and to reduce moisture content. In addition, these 
materials may be used to balance the $\mathrm{C} / \mathrm{N}$ ratio, increase its porosity and prevent excessive compaction of the composting materials.

The objectives of the present work are to examine the optimal ratio of waste activated sludge/inactive fillers and waste activated sludge/microorganism for composting under aerobic conditions. The most important physico-chemical parameters such as temperature, $\mathrm{pH}, \mathrm{TOC}$, total $\mathrm{N}$ and $\mathrm{C} / \mathrm{N}$ ratio were monitored.

\section{Materials and Methods}

\subsection{Preparation of Composting Mass}

Waste activated sludge obtained from Vinh Loc Industrial Park located in Ho Chi Minh City, Vietnam, was dewatered to a water content of approximately $60-70 \%$. Fifty $\mathrm{kg}$ of dewatered sludge were prepared and composted in a batch composting system. The sludge was then minced and mixed with inactive filler as the bulking agent. The inactive filler was obtained from rubber production factory after grounding to a particle size of 1-2 $\mathrm{cm}$. Microbe-Lift IND was a microbial liquid culture that is 5 to 10 times more potent than conventional microorganism produced by Ecological Laboratories, the United States. It can break down fecal compounds, converting the nutrients in these compounds into more readily available formulations, accelerating the biological oxidation of organic compounds, substances slow organic decomposition [5].

\subsection{Composting Experiments}

The composting experiments were conducted in iron sheets of $1 \mathrm{~m} \times 0.5 \mathrm{~m}$. The reactor was equipped with eight perforated plastic pipes supplying air to the compost pile. A fine screen mesh was installed above the reactor bottom to segregate the compost pile from the aeration pipe. The composting material was manually turned once a day to ensure a homogeneous air distribution. Temperature was monitored before and after turning. Samples were withdrawn to measure moisture content, $\mathrm{pH}$, total $\mathrm{N}, \mathrm{TOC}$ at $1,10,20,30,45$, 50 days of testing. At the end of study, samples were analyzed $\mathrm{pH}, \mathrm{TOC}$, total $\mathrm{N}$, moisture content, TS, VS, $\mathrm{K}_{2} \mathrm{O}, \mathrm{P}_{2} \mathrm{O}_{5}$ and heavy metals.

The series of composting experiments were designed at different conditions: 6 aerobic composting batches with ratios of sludge and inert fillers 1:0, 1:0.3, $1: 0.35,1: 0.4,1: 0.45,1: 0.5 ; 6$ aerobic composting batches supplemented with microbiological preparations as ratios 1:0, 1:0.02, 1:0.05, 1:0.08 and 1:0.1.

\subsection{Analytical Methods}

Total solid and volatile solid were determined by US EPA Method 1684. TOC, Total N, $\mathrm{P}_{2} \mathrm{O}_{5}, \mathrm{~K}_{2} \mathrm{O}$ were analyzed by TCVN 8941:2011, TCVN 6498:1999, TCVN 5256:2009, TCVN 8560:2010, respectively. Heavy metals were determined by AAS (Atomic Absorption Spectrophotometer) according to US EPA Method 3051A and SMEWW 3125B:2012 [6].

\section{Results and Discussion}

\subsection{Temperature}

Fig. 1 shows the temperature variations, a function of time.

Temperature variations of all batches were similar following "fast-declining-stable". The early stage of the test increased slowly due to microbial adaptation, then temperature increased rapidly after 7 days and reached $53.5^{\circ} \mathrm{C}$ after 15 days in $\mathrm{MH} 2$, higher than 9.5 ${ }^{\circ} \mathrm{C}$ compared with the highest temperature in the control batch. Temperature of this study was less than some previous studies such as composting from the pig manure $\left(55{ }^{\circ} \mathrm{C}\right)$ [7], from the olive mill waste $\left(62.3^{\circ} \mathrm{C}\right)$ [8]. The high temperatures of the batches were maintained for 3-5 days and reached the optimum temperatures for composting $\left(40-60{ }^{\circ} \mathrm{C}\right)$. The temperatures of sludge and inactive filler mixture were similar, and the highest value was achived after 23 days, it was slower than the compost with microbial incubation. 


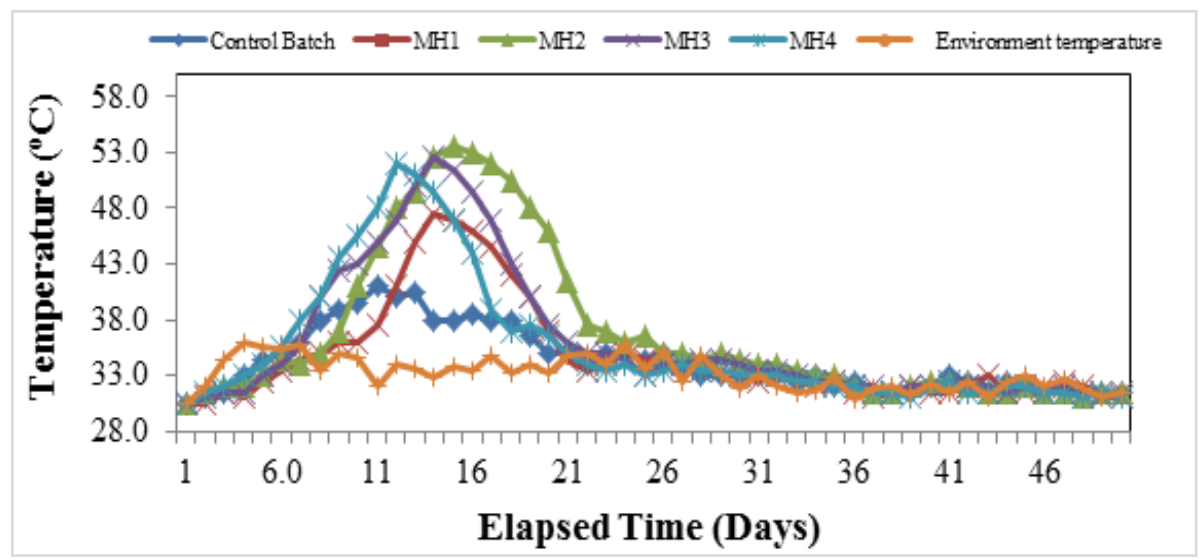

Fig. 1 Variation of temperature through time.

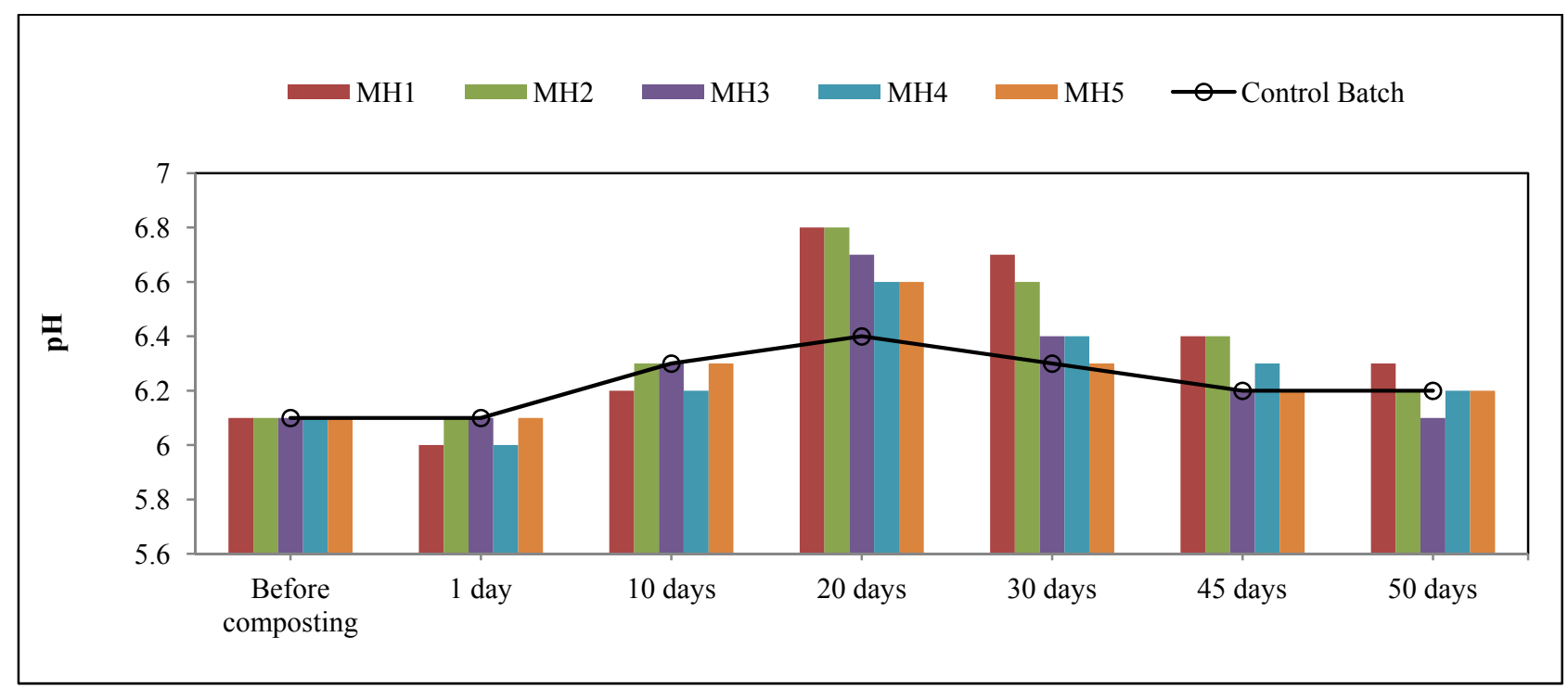

Fig. 2 Variation of $\mathrm{pH}$ through time.

\section{$3.2 \mathrm{pH}$}

The $\mathrm{pH}$ variations were shown in Fig. 2.

The $\mathrm{pH}$ of early stage were reduced by bacterial adaptation. Bacterias consumed the substrate and organic compounds for growth, released organic acids at the same time, the accumulation of these acids led to decrease of the $\mathrm{pH}$. Then, the $\mathrm{pH}$ increased rapidly from day 2 to day 20 of the test. It indecated that decomposition of organic acids by microorganisms has occurred in each batch, $\mathrm{pH}$ values gradually stabilized at the end of study. The $\mathrm{pH}$ values of batches which supplemented the microorganism were from 6.0-6.7. The similar $\mathrm{pH}$ values were obtained in the batches mixed with inactive filler (6.0-6.8). It was in the optimum $\mathrm{pH}$ range for bacterial activities (5.5-8.5).

\subsection{Moisture}

The changes of moisture were shown in Fig. 3.

Moisture is one of the important factors for bacterial growth. During the test, the moisture tended to decrease significantly due to the evaporation of water from the bed. In the first 25-30 days, the moisture content of the compost was monitored regularly. In the case, the moisture was too low, the water would be replenished to maintain optimal humidity (50-60\%). After 30 days of the test, the composting was gradually stabilized, stopping adding water so that the moisture contents of the composting 


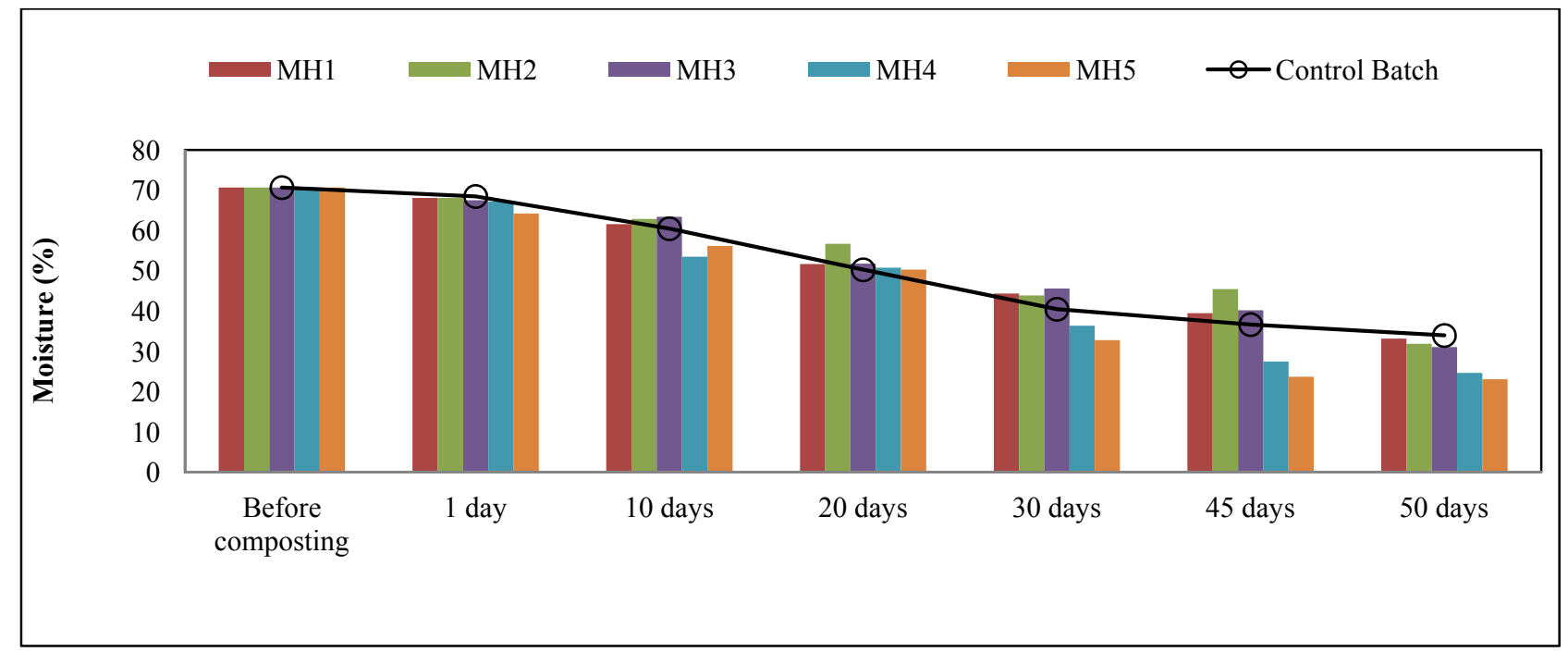

Fig. 3 Variation of moisture through time.

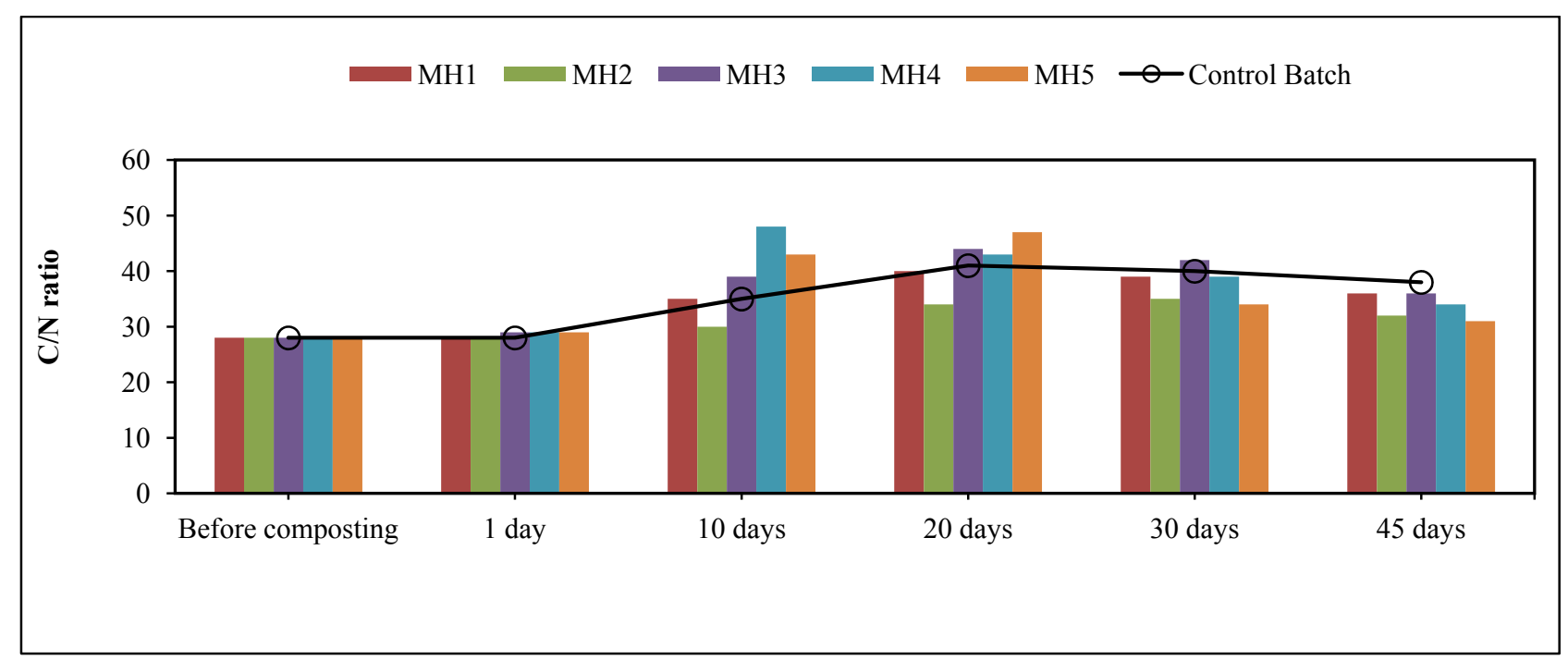

Fig. 4 Variation of $\mathrm{C} / \mathrm{N}$ through time.

were maintained naturally. The moisture content of test was achieved 10TCN 526: 2002 (humidity < $35 \%)$. For the inert filler batches, the moisture content varied between 50.3-68.5\% for the first 20 days and decreased gradually until the end of the test.

\subsection{C/N Ratios}

The changes of $\mathrm{C} / \mathrm{N}$ of study were shown in Fig. 4. The $\mathrm{C} / \mathrm{N}$ ratio is an indicator of the decomposition of organic fertilizer. Fig. 4 showed that the $\mathrm{C} / \mathrm{N}$ ratios of study were in the range of 21.3 to 28.4 and were within the optimum range for sludge decomposition.
At the end of the experiment, the $\mathrm{C} / \mathrm{N}$ ratio in the $\mathrm{MH}$ was less than the initial value (28.1), the $\mathrm{C} / \mathrm{N}$ ratio of $\mathrm{MH} 2$ was the lowest with the value of 21.3. However, due to the low nitrogen content, the $\mathrm{C} / \mathrm{N}$ ratio was still high. The results of this study were in a higher $\mathrm{C} / \mathrm{N}$ ratio than that of Nguyen Van Phuoc, et al. [9]. The $\mathrm{C} / \mathrm{N}$ ratios of batches mixed with inactive sludge were higher (32-37) than that of the microbial inoculation.

Results of study are presented in Table 1.

Table 1 shows that the quality of sludge after composting of all batches met the standard of organic compost except the low total nitrogen. Since the 
Table 1 The analytical results of sludge after composting.

\begin{tabular}{llllllll}
\hline Parameters & Unit & Control batch & MH1 & MH2 & MH3 & MH4 & 10TCN 526:2002 \\
\hline $\mathrm{pH}$ & - & 6.2 & 6.1 & 6.1 & 6.2 & 6.1 & $6.0-8.0$ \\
Moisture & $\%$ & 34.0 & 33.0 & 30.4 & 32.5 & 33.4 & $<35$ \\
$\mathrm{TS}$ & $\%$ & 65.6 & 68.9 & 68.6 & 67.8 & 67.7 & - \\
$\mathrm{VS}$ & $\%$ & 48.1 & 48.3 & 47.7 & 48.3 & 47.7 & - \\
$\mathrm{C} / \mathrm{N}$ & - & 27.6 & 25.2 & 21.3 & 23.6 & 23.1 & - \\
$\mathrm{TOC}$ & $\%$ & 19.6 & 18.4 & 16.6 & 17.0 & 17.3 & $>13$ \\
Total N & $\%$ & 0.71 & 0.73 & 0.78 & 0.72 & 0.75 & $>2.5$ \\
Total P & $\%$ & 3.00 & 3.08 & 2.92 & 2.74 & 2.71 & $>2.5$ \\
$\mathrm{~K}_{2} \mathrm{O}$ & $\%$ & 1.49 & 1.50 & 1.50 & 1.52 & 1.51 & $>1.5$ \\
E. coli & $\mathrm{MPN} / \mathrm{g}$ & $1.1 \times 10^{4}$ & $\mathrm{NA}$ & $\mathrm{NA}$ & $\mathrm{NA}$ & $\mathrm{NA}$ & - \\
Salmonella & $\mathrm{MPN} / 25 \mathrm{~g}$ & $\mathrm{NA}$ & $\mathrm{NA}$ & $\mathrm{NA}$ & $\mathrm{NA}$ & $\mathrm{NA}$ & 0 \\
\hline
\end{tabular}

*NA: Non- available.

temperature of the control batch was not high and the maximum temperature was maintained at a short time (40-41 ${ }^{\circ} \mathrm{C}$ for 3 days), after the end of the test, E. coli was still detectable in compost. However, after 50 days of study, the batches added microbial products were more stable, resulting in no presence of $E$. coli and Salmonella in compost product.

The results of the analysis indicated that the $\mathrm{MH} 2$ (sludge:microbial ratio of $1: 0.05$ ) had the highest efficiency of composting, all the parameters met the standard 10TCN 526: 2002.

The highest compost efficiency of batches mixed with inactive filler was obtained at $\mathrm{MH} 1$ (sludge/inactive filler ratio of 1:0.3). The TOC of it dropped from $36.8 \%$ to $17.3 \%$, maximum temperature increased to $58.2{ }^{\circ} \mathrm{C}$, and other parameters met standard organic fertilizer 10TCN 526: 2002 excluding total $\mathrm{N}$ content. Therefore, to improve the compost quality and meet the market demand, addition of nitrogen is necessary.

\section{Conclusion}

The biological sludge obtained from the Vinh Loc Industrial Park had potential as a raw material for producing compost. The sludge was mixed with inactive fillers, the nutritional parameters of mixture increased over time as the effective phosphorus content, potassium and some other criteria met fertilizer standard 10TCN 526: 2002 as TOC, moisture.

The results indicated that $\mathrm{MH} 1$ (the ratio of sludge/inactive filler of 1/0.3) had the highest composting efficiency with the highest reduction of total carbon content from $36.8 \%$ to $17.3 \%$.

The optimum mixing ratio of sludge and microorganism was 1:0.05. Thus, the microbial composition had a positive effect on the composting, the quality of the compost was higher than that of the non-supplementary product, favorable environment for the composting, minimizing odor.

The result of this study indicated that this model can be applied in centralized wastewater treatment plants to address the emerging sludge problem. It is necessary to classify biological sludge and chemical sludge in order to have optimum treatment for each type of sludge, especially the reuse of sludge effectively.

Research on the effectiveness of composting product from bio-sludge applied to a number of vegetables, crops and ornamental plants need carried out for practical application.

\section{Acknowledgment}

This research was supported by the ministry-level research project of the Ministry of Natural Resources and Environment in 2016.

\section{References}

[1] Suntud, S. 2014. "Innovative Sludge Management of 
Urban and Industrial Wastewater." Enviro. Technol 35: 185-92.

[2] Zopas, A. A., Arapoglou, D., and Panagiotis, K. 2003. "Waste Paper and Clinoptiolite as Bulking Material with Dewatered Aerobically Stabilized Primary Sewage Sludge (DASPSS) for Compost Production." Waste Management 23: 27-35.

[3] Patni, N. K., Kannagara, T., Nielsen, G., and Dinel, H. 2001. "Composting Caged-Layer Manure in Passive Aerated and Turned Windrows.” ASAE paper No. 012271. American society of Agricutural Engineers, St. Josepth, Michhigan, USA.

[4] Anastasi, A., Varese, G. C., Voyron, S., Scannerino, S., and Fillipello, M. V. 2004. "Characterization of Fungal Biodeversity in Compost and Vermicompost." Compost Sci. Util. 12: 185-91.
[5] Liang, C., Das, K. C., and McClendon, R. W. 2003. "The Influence of Temperature and Moisture Content Regimes on the Aerobis Microbial Activity of a Biosolids Composting Blend." Bioresource Technology 86: 131-7.

[6] APHA. 1995. Standard Methods for the Examination of Water and Wastewater. APHA, Washinton, DC..

[7] Huang, G. F., Wong, J. W. C., Wu, Q. T., and Nagar, B. B. 2004. "Effect of $\mathrm{C} / \mathrm{N}$ on Composting of Pig Manure with Sawdust." Water Management 24: 805-13.

[8] Cayuela, M. L. 2006. "Evaluation of Two Different Aeration Systems for Composting Two-Phase Olive Mill Wastes." Biochemistry 41: 616-23.

[9] Nguyen Van Phuoc, et al., 2016. Research on Inactive Compost with Biosludge and Rubber Filler in Binh Duong Province. Environmetal Journal Topic No. 1: Page 31-38. 